\title{
The Effects of Moving Animation on Recall, Hedonic and Utilitarian Perceptions, and Attitude
}

\author{
Yee-Lin Lai, Kevin K. Y. Kuan, Kai-Lung Hui, and Na Liu
}

\begin{abstract}
An increasing number of firms are investing in moving animation to create more vivid and attractive Web sites. Animated contents are usually invisible to search engines or Web spiders, involve lengthier download time, and are inaccessible to less technology-savvy users who are not equipped with the necessary software or browser plug-ins or users who are wary of malicious Internet downloads. The development costs of animated Web sites are considerably higher too compared with static Web sites. Do the benefits provided by animation justify all of these potential weaknesses? We answer this question by studying the effects of moving animation on consumer responses toward a product. Using an exploratory laboratory experiment, we found that moving animation enhances product recall, perceived product values in terms of the hedonic and utilitarian dimensions, and attitude toward products that are high on the hedonic dimension. It does not, however, enhance consumer attitude toward products that are more "utilitarian" in nature. We draw related managerial implications from these findings.
\end{abstract}

Index Terms-Attitude, hedonic, moving animation, recall, utilitarian, web design.

\section{INTRODUCTION}

Animation can explain whatever the mind of man can conceive. This facility makes it the most versatile and explicit means of communication yet devised for quick mass appreciation.

A NIMATION is prevalent on the Internet today. Increasingly, advertisers are using animated instead of static images in their online advertising campaigns [1], and Web sites often exhibit featured products using computer-generated movie clips. On the client/user side, animation viewing software such as the Adobe Flash ${ }^{\circledR}$ player and Shockwave ${ }^{\circledR}$ player are garnering good support too-as of June 2008, the Flash ${ }^{\circledR}$ player and Shockwave ${ }^{\circledR}$ player enjoy penetration rates of almost $99 \%$ and 58\% among PC users in mature markets. The ubiquity of this type of software underscores the proliferation of animation in online contents.

Manuscript received July 24, 2007; revised March 29, 2008, August 16, 2008 and October 24, 2008. First published June 16, 2009; current version published July 17, 2009. Review of this manuscript was arranged by Department Editor R. Sabherwal.

Y.-L. Lai is with the Agency for Science, Technology and Research, 138632 Singapore (e-mail: laiyeeli@comp.nus.edu.sg).

K. K. Y. Kuan is with the Department of Information Systems, College of Business, City University of Hong Kong, Kowloon, Hong Kong (e-mail kkykuan@cityu.edu.hk).

K.-L. Hui is with the Department of Information Systems, Business Statistics and Operations Management, Hong Kong University of Science and Technology, Kowloon, Hong Kong (e-mail: klhui@ust.hk).

N. Liu is with the Department of Information Systems, National University of Singapore, 119260 Singapore (e-mail: liuna@comp.nus.edu.sg).

Color versions of one or more of the figures in this paper are available online at http://ieeexplore.ieee.org.

Digital Object Identifier 10.1109/TEM.2009.2023454
It is of little doubt that animation often enhances the visual appeal of a Web site, and it may help attract viewers' attention to certain sections or contents of the site. However, these benefits come with some potential costs-animation may distract users and reduce their information search efficiency [2]. If improperly presented, animation could annoy people and lead to negative perceptions toward a Web site [3], [4].

Practically, it is often more costly to develop animated Web pages. For example, the most popular software for creating animated clips on the Web, the Adobe Flash ${ }^{\circledR}$, is currently selling for US\$699. The creation of animation calls for special skills and knowledge too, and more time is needed in the development (it is not unusual for developers to devote several weeks of time just to create short animations of several minutes). Animated contents are mostly embedded as binary objects rather than HTML texts on Web pages, and hence they are often "invisible" to automated search engines or Web "spiders." Because the display of animation calls for special "viewers" or browser plug-ins, and the enabling of client-side scripting or object downloads, animation is often inaccessible to less technology-savvy users or users who concern about the security and privacy of their computer systems [5].

Given these potential weaknesses, it is noteworthy to observe animation being widely deployed in many Web sites for improving "look and feel," increasing product comprehension, and attracting user attention [2]. Since animation may direct user focus to certain products on a Web page, and it could potentially increase the vividness of the animated products [3], [6], it is interesting to study how it affects consumer perception and evaluation of the products. Our research questions are thus posed as follows:

\section{Would animation affect how consumers perceive a product, or change their attitude toward a product? Would the effect of animation vary across products of different nature (utilitarian vis-à-vis hedonic)?}

In an exploratory research, we look into the effects of animation from three perspectives: recall, the hedonic and utilitarian perceptions of a product, and attitude toward the product. We are particularly interested in the kind of animation that involves moving objects (hereafter we call it "moving animation") and that does not provide extra information to users. This type of animation can generally be classified as "without initiative" animation; that is, there is no direct interaction with users [7]. It was frequently used in previous research on the attention-grabbing effect of animation (see, e.g., [4]).

One of our objectives is to examine if moving animation can generate better recall of a product on a Web site, which is a useful indicator of whether the Web site can create a strong impression on consumers. We further study the interaction of 
animation with product nature and its effects on consumers' perceptions of the products. Recent research has found that hedonic and utilitarian considerations can affect the way products are acquired and consumed [8], suggesting that promotional strategies for particular product genres may vary according to their nature [9]. It is important to consider if animation affects consumers' perceptions of and attitudes toward "hedonic" and "utilitarian" products.

\section{LITERATURE REVIEW}

In this section, we review previous literature on animation, its key characteristics, and impact on consumers and consumers' product perceptions. Then, we present our theoretical hypotheses in the next section by integrating the findings from this literature.

\section{A. Animation}

Animation has been defined as a dynamic visual statement, form, or structure that evolves through movement over time [10]. It is often deployed in Web sites for improving "look and feel," enhancing product visualization so that products are more comprehensible, and attracting user attention [2].

In general, moving animation attracts user attention because it encompasses motion [3], [11] and is visually distinctive from the rest of the stimuli (viz., other static components of a Web page [12]). The objects in a moving animation are likely to stand out from other static objects, and, once viewers' attention is captured, these distinctive moving objects may enhance their memory of the emphasized contents [13]. The viewers may then exhibit selective processing of information, leading to quicker responses, better recall, and deeper impression of the animated contents (cf. other static contents [4]).

Because of the dynamism conveyed by the vivid transformation in contents, moving animation may be perceived as emotionally interesting, concrete, imagery provoking, and more proximate to viewers than static contents [3], [6]. Hence, a Web site that incorporates moving animation may arouse viewers. Such arousal could translate into emotional evaluation of the featured contents and enhance viewers' overall perception of the Web site and its contents [14].

Prior research has mostly studied the impact of animation in the context of banner advertisements (ads) on Web sites. For example, Hamilton [15] has suggested that viewers are repelled by blinking banner ads, whereas Hong et al. [2] have found that animated flashing items facilitate quicker location of the items by consumers. Animated banner ads may increase brand awareness, brand preference, and purchase intention as compared with static ads [16]. They affect viewer cognition toward a brand too [13].

Overall, the finding that moving animation attracts user attention seems to be robust across the earlier cited studies, and it affects user preferences for products [7]. However, to date there is no systematic study of how moving animation interacts with product nature on a Web site to affect consumer perceptions and preferences of products. It would be useful to observe if previous results on banner ads continue to hold for Web sites that display products with different characteristics.

\section{B. Product Perception: Hedonic and Utilitarian}

Consumer researchers have recognized the "experiential" aspects of consumption [17]. In general, people appreciate two dimensions of value in shopping - they may enjoy a utilitarian outcome from the pursuit of an intended consequence and, at the same time, a hedonic outcome related to fun, playfulness, and excitement [18].

Broadly defined, the hedonic dimension of consumption value is related to sensory attributes and focuses on consummatory affective gratifications. By contrast, the utilitarian dimension is related to functional and nonsensory attributes, focusing on instrumental expectations [19], [20]. Any consumption object, be it a product or service, can be evaluated in terms of the utilitarian and hedonic values that it provides to consumers, but such values need not be mutually exclusive or equally salient [8], [21], and they are shaped by the particular consumption context and intention of the consumers [22], [23].

Products that are high on the hedonic dimension provide more experiential consumption, fun, and excitement [21]. Their consumption is usually motivated by one's desire for fantasy, fun, and sensory pleasure. The prior literature has designated hedonic consumption to be multisensory, being more susceptible to receipt of experience in multiple sensory modalities including tastes, sounds, scents, and visual images [24]. On the other hand, products that are high on the utilitarian dimension are largely instrumental; their consumption is usually motivated by functional needs.

The Internet provides a flexible environment for consumers to experience different aspects of products [6]. Because of low visiting cost to Web sites, Internet consumers are more likely to visit a store to try out products without any intention of buying [22], [25]. This flexibility in shopping and the higher tendency to try new products or services may open the possibility for online stores to affect consumers' product perceptions through carefully designed stimuli (much like the way banner ads are used to shape consumer brand perceptions and preferences). Since moving animation is pervasive on the Internet and has often been found to arouse consumers, it would be interesting to observe if it could also affect how consumers appraise products.

Practically, studying what shapes product perceptions may provide researchers and managers a fresh approach to model marketing problems. Since previous research has shown that differences in hedonic and utilitarian perceptions can affect the way a product is regarded, acquired, consumed, and (even) forfeited [8], it is important to understand how these perceptions came about.

\section{HYPOTHESES}

We approach the effect of moving animation on products from three perspectives - recall, hedonic/utilitarian perceptions, and attitude. These three variables variously measure whether the animated products are cognitively or affectively enhanced to consumers. 


\section{A. Recall}

One method to verify the extent to which a message has imprinted on a person is to measure its recall by the person at a later stage. Recall is a good measure of attention because it reflects the quality of attention in addition to being a quantitative measure of time [26]. It has been commonly used in information systems research to assess the effectiveness of interface design in information transmission [27]-[29] and if Web stimuli such as flashing items could affect consumer processing of product information [2].

The limited capacity theory posits that the processing of information by human being involves continuous and simultaneous operation of several subprocesses, including encoding, storage, and retrieval [30]. Since human's mental resources are limited, not all information can be encoded and stored in memory for retrieval.

However, studies have shown that objects that elicit orienting responses in consumers may entail greater allocation of cognitive resources in encoding and storing the contents inside the objects [3], [4]. Since moving animation encompasses dynamic and orienting objects which may draw selective attention from consumers, consumers may allocate more resources to encode and store the animated components on a Web site (relative to nonanimated components). Accordingly, we posit the following hypothesis.

\section{Hla: The recall of animated contents is higher in a Web site exhibit- ing both animated and static (nonanimated) contents than a Web site with only static contents.}

Since human being has limited capacity to process information, allocating more resources to animated components would reduce the resources available to other components. Hence, the encoding and storage of static components would be reduced, leading to lower recall.

$H 1 b$ : The recall of static contents is higher in a Web site exhibiting only static contents than a Web site with both animated and static contents.

\section{B. Perception of Product Value}

As we reviewed above, individuals' consumption of any product encompasses both utilitarian and hedonic values. Past research has shown that the perceptions of these two dimensions of values are affected by the shopping environment, process, and atmosphere [18], [31]. Shopping inside a pleasant environment can be intrinsically gratifying and fun [24], and so the experience per se provides hedonic value. Similarly, shopping inside an environment that facilitates product choice and efficiency can enhance utilitarian value. The design of the shop or its atmosphere can be more important than the product itself in the purchase decision [32].

In general, environmental stimuli, including any verbal or nonverbal cues, objective or subjective features of the store and product, and semantic or syntactic communication contents, affect consumer cognition, affect, and behavior. In particular, the rich literature in consumer behavior has suggested that store characteristics (which is one type of environmental stimuli) could shape cognitions and affects such as knowledge structure, beliefs, and emotions toward a product [24].

In online shopping, the environment and atmosphere is created and shaped by the design of the Web site. Internet businesses often play the role of physical buildings [33], and, to consumers, the Web site is basically the store [34]-[36]. Hence, the design of a Web site, similar to the layout and ambience of a physical store, could possibly shape consumers' cognitive and affective views of a product. While there is great diversity in defining consumer cognition and affect, the utilitarian and hedonic classification of values is a parsimonious typology that is widely accepted in consumer behavior research (see, e.g., [18], [23]).

Since moving animation delivers contents in a more vivid way, arouses consumers [3], and increases novelty and entertainment values to consumers [2], [37], [38], it may serve as a salient environmental stimulus that influences consumer experience of the product on a Web site [39]. Previous research has shown that pleasure and arousal could shape the hedonic and utilitarian assessments of TV ads [40]. Here, we posit that moving animation creates a more exciting and playful environment, which may arouse consumers, subsequently raising their perception of hedonic value carried by the product.

\begin{abstract}
H2a: The hedonic perception of a product is higher in a Web site exhibiting both animated and static contents than a Web site with only static contents.
\end{abstract}

Similarly, a Web site that contains only static contents may serve as an environmental stimulus that projects an impression of being efficient, instrumental, and utilitarian. Unlike moving animation, a Web site with only static contents directly conveys product information to consumers without any distraction; lacking an animated stimulus, consumers can possibly devote more attention to the details of the contents on a Web site [4]. Hence, it is more likely that consumers would appreciate the utilitarian aspects of the product (features, functionality, etc.). This leads to our next hypothesis.

\section{$H 2 b$ : The utilitarian perception of a product is higher in a Web site exhibiting only static contents than a Web site with both animated and static contents.}

$\mathrm{H} 2 \mathrm{a}$ and $\mathrm{H} 2 \mathrm{~b}$ posit that the hedonic and utilitarian perceptions of products are affected by the use of moving animations on a Web site. However, it is unclear if the perceived magnitudes of changes in product perceptions vary with the nature of the products. In psychophysics, the Weber's law posits that the change in a person's level of sense perception depends on the initial intensity of the stimulus that is acting on the senses. ${ }^{1}$ For example, the same amount of change in weight would be perceived as less significant when the initial weight is high than when the initial weight is low. A similar observation has been

\footnotetext{
${ }^{1}$ Mathematically, Weber's law states that the "just noticeable difference" of a change in a stimulus, $\Delta I$, is directly proportional to the stimulus, $I$, itself. That is, $\Delta I / I=K$, where $K$ is a constant specific to a sense mode or dimension, such as pitch, brightness, etc. [41], [42]. The law is often called Weber-Fechner law in view of the contributions made by Fechner in scaling the sensations in terms of the physical intensity of the stimuli that a person experienced [43]. The law has been well applied to computer graphics and image processing (see, e.g., [44], [45]).
} 
made for other perceptual units, including loudness, brightness, taste, velocity, duration, etc. [46].

The Weber's law has been well tested in perceptions of physical stimuli such as weight, vision, and sound, and it has also been applied to consumer behaviors, such as the perceptions of wage and price changes, used car values, quality, and advertising intensity (see, e.g., [41], [42], [47], [48]). It could well be possible that the perceptions of hedonic and utilitarian values (the key perceptual units under consideration) of a product may follow the law too.

In particular, we posited in $\mathrm{H} 2 \mathrm{a}$ that moving animation (an external stimulus) raises consumer perception of hedonic value of a product, but, if the initial hedonic perception of the product is already high, then the resulting impact caused by the animation on consumers may be less significant. Conversely, for a product that is originally high in utilitarian value, presenting its contents in static format may not significantly increase its utilitarian perception to consumers. Hence, we posit the following (exploratory) hypotheses:

\footnotetext{
H3a: The effect of moving animation on a product's hedonic value is weaker for a product that is high on the hedonic dimension than a product that is high on the utilitarian dimension.
}

$H 3 b$ : The effect of static contents on a product's utilitarian value is weaker for a product that is high on the utilitarian dimension than a product that is high on the hedonic dimension.

\section{Attitude Toward a Product}

Attitude is defined as the predisposition to respond in a particular way toward a specified class of objects [49]. Previous research has posited that attitude comprises affective and cognitive components [21], [50], [51]. ${ }^{2}$ The affective component comprises feelings formed without conscious thoughts, and they can be expressed in verbal statements of "affect." The cognitive component comprises ideas and beliefs formed through conscious thoughts, and they can be expressed in verbal statements of "beliefs" and "values." The existing literature, however, has not systematically explored the effects of Web site features on consumer attitude. It is possible that the design of a Web site could affect consumer attitude toward a product [23].

In particular, animation may exhibit an "attraction effect"if consumers are presented with two products that are good in different aspects, when a third product that is dominated by the first product but not by the second product is introduced, people tend to find the first product more attractive [52]. Such an "attraction effect" is accentuated when the dominating product is animated [7], which implies that animation may affect the attitude of consumers toward a product relative to their attitude toward other products.

Similarly, previous research has found that animated advertisements generate more positive attitude toward a product than static ones [53]. However, this effect could be moderated by the fit with the purpose of the consumption [39]. In the consumer

\footnotetext{
${ }^{2}$ Some researchers have separated a third, behavioral, component, from the affective and cognitive components, and treated the attitude component as one's action tendencies (see, e.g., [51]).
}

behavior literature, "fit" has been shown to be an important factor in shaping consumer attitude in the case of Web site-product image fit [54] and brand image-product function fit [55]. Since product image and function are both characteristics that variously shape the utilitarian and hedonic values of a product, it is possible that whether a product is perceived to be "hedonic" or "utilitarian" may interact with the nature of its host Web site to affect consumers' overall attitude toward the product.

Utilitarian, goal-oriented consumption is mostly cognitively driven, instrumental, and often accomplishes functional or practical tasks [19]. A Web site with only static contents may disseminate the necessary information in a straightforward manner to facilitate consumers in seeking to understand the features and functionalities of a product that provides high utilitarian value. Displaying such a product using moving animation, however, may not enhance consumers' experience because the animation may unnecessarily excite and arouse consumers, which distract their attention away from the utilitarian features (which is the basic strength) of the product. This could lead to lower overall attitude.

By contrast, hedonic consumption is characterized by an affective and sensory experience of aesthetic or sensual pleasure, fantasy, and fun [17]. Moving animation can probably enhance such hedonic consumption because of the added vividness, which helps excite and arouse consumers (e.g., previous research has found that regardless of contents, moving television images induced higher skin conductance responses, which is a physiological assessment of autonomic arousal, than still images). Once consumers are aroused, they appreciate pleasurable sensory stimuli, and products that are high on hedonic value could accentuate such stimuli. Hence, using animation on such products may potentially raise consumer attitude. Summarizing the earlier discussion, our last hypothesis is given as follows.

\begin{abstract}
H4: The effect of moving animation on consumer attitude toward a product depends on the nature of the product. Moving animation leads to higher consumer attitude for products that are high on hedonic value. By contrast, static contents (without animation) lead to higher attitude for products that are high on utilitarian value.
\end{abstract}

\section{Methodology}

We conducted a laboratory experiment to test the above hypotheses. Eighty undergraduate students were recruited as subjects in a 30-min experiment. We provided the subjects with a token monetary reward as participation incentive. The average age of the subjects was 21 , and $60 \%$ of them were male.

We manipulated two factors in the experiment. First, we selected two types of products - one that is high on utilitarian value and the other high on hedonic value. For the "hedonic" type, we selected portable game console and robotic dog. For the "utilitarian" type, we selected printer and calculator. For each product, we created two Web pages, one incorporating moving animation in some of the contents whereas the other was completely static. We designed the two Web pages in such a way that when the moving animation came to a standstill, the Web page appeared exactly identical to the completely static version. Hence, the same amount of information (graph, slogan, textual 


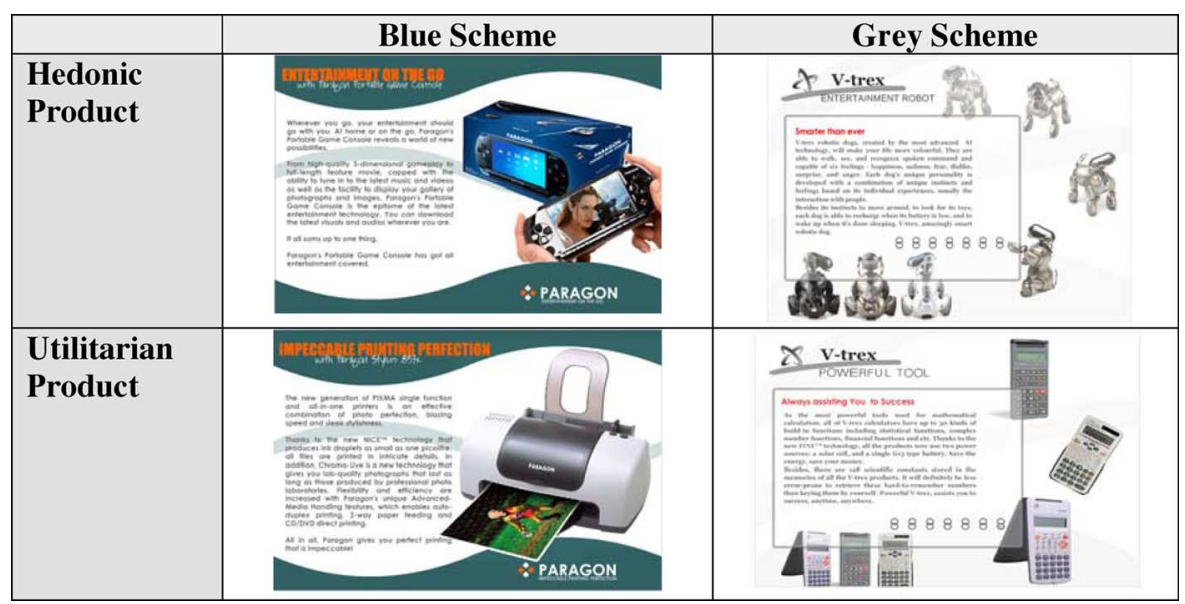

Fig. 1. Design schemes of web pages.

description, etc.) was displayed in both the animated and static versions of the Web pages.

We created all moving animations using Adobe Flash ${ }^{\circledR}$. For convenience, we labeled the pages with portable game console and printer as the "blue scheme" and the ones with robotic dog and calculator as the "gray scheme." Fig. 1 shows the static versions of the Web pages that were used in the experiment (the animated versions were identical except that some parts of the pages would move and hence were animated when loaded).

As shown in Fig. 1, the layout of the pages was standardized. Each Web page consisted of a brand name, logo, slogan, picture, and brief description of the exhibited product. For the moving animations, we incorporated effects including blinking, motion, and gradual fade-ins. The animations were programmed in such a way that the logos and pictures (for the blue scheme) or logos and slogans (for the gray scheme) would continuously animate throughout the browser session, whereas the brand name would animate only initially (when the pages were first loaded). In the static treatment, all pages appeared as shown in Fig. 1. No animation was involved. We used fictitious brand names for all products to avoid a priori brand influence.

We conducted a pretest before the experiment to ensure that the selected products were appropriate (i.e., they carry the desired hedonic or utilitarian values). Twenty university students who did not participate in the subsequent main experiment were tasked to read a short description with a picture of a product in each category (i.e., hedonic vis-à-vis utilitarian). They were then requested to rate their perceptions along the hedonic (fun, exciting, delightful, thrilling, and enjoyable) and utilitarian (necessary, effective, helpful, functional, and practical) dimensions on a 7-point scale. ${ }^{3}$ Table I presents the mean hedonic and utilitarian values for each of the included products.

Pairwise $t$-tests show that there were significant differences in hedonic and utilitarian values across the portable game console/calculator, portable game console/printer, robotic $\operatorname{dog} /$ calculator, and robotic dog/printer pairs, and all $p$-values

\footnotetext{
${ }^{3}$ The measurement items for hedonic/utilitarian perceptions were adapted from Voss et al. [20]. The full list of items is presented in the Appendix.
}

TABLE I

AVERAGE HEDONIC AND UTILITARIAN SCORES

\begin{tabular}{|l|r|r|r|r|r|}
\hline & \multicolumn{2}{|c|}{ Hedonic Score } & \multicolumn{2}{|c|}{ Utilitarian Score } & \multirow{2}{*}{ t } \\
\cline { 2 - 6 } & Mean & S.D. & Mean & S.D. & \multicolumn{1}{c}{ t } \\
\hline Game Console & 5.13 & $\mathbf{0 . 2 0 6}$ & 3.43 & 0.248 & 6.01 \\
\hline Robotic Dog & 5.05 & 0.202 & 2.83 & 0.188 & 8.43 \\
\hline Calculator & 3.06 & 0.241 & 5.66 & 0.192 & -8.09 \\
\hline Printer & 4.88 & 0.218 & 6.03 & 0.175 & -5.90 \\
\hline
\end{tabular}

were smaller than 0.05 . Hence, we concluded that portable game console and robotic dog were good representatives of products that are high on hedonic value, and calculator and printer were good representatives of products that are high on utilitarian values.

To increase the cost-effectiveness of the experiment, we asked each subject to view the Web pages of two products, where the two products differed in terms of color scheme (blue visà-vis gray) and nature (high on hedonic vis-à-vis utilitarian values). ${ }^{4}$ So, each subject provided two sets of responses in the experiment, and we pooled their responses in the analysis. To avoid demand bias, we restricted the subjects to view either the static or animated version but not both. Hence, animation was a between-subject factor, and product type was both a betweenand within-subject factor. We further randomized the sequences of the Web pages to eliminate any possible ordering effect. Each subject was given 2 min to view the Web page of a product. After that, they were asked to answer several questions pertaining to their recall and perception of and attitude toward the product.

To prevent subjects from memorizing the task and questions, we added a "filler" task with questions that were completely different from the other two tasks after they viewed the first product to distract their attention. After completing the filler task, we presented subjects the second product. Fig. 2 shows the actual sequence of events in the experiment.

\footnotetext{
${ }^{4}$ In other words, each subject would always view one hedonic and one utilitarian product and one blue-scheme and one gray-scheme product.
} 


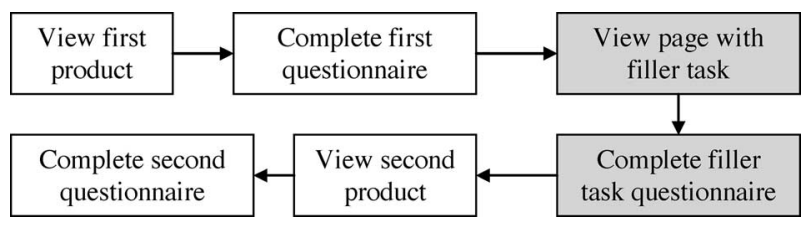

Fig. 2. Experimental flow.

\section{A. Dependent Measures}

1) Recall: Recall refers to the amount of information that the subjects can remember about a product. After the subjects finished viewing a product, the Web site was culminated and they were asked to write down the product category (product category recall), brand name (brand recall), color of the logo (color recall), and slogan of the product (slogan recall). Further, the subjects were also asked to record any other details that they could recall, such as the technologies used in the products, or other product characteristics that were mentioned in the description (recall of other information).

We summed the first four information to derive a "recall-A" measure (for the animated components). We designated the recall of other information as "recall-S" (for the relatively static information). We adopted the principles in [56] to judge the correctness of the recall results. Two independent coders inspected the subjects' answers to check if they conveyed the same ideas as presented on the Web pages. The average intercoder reliability was 0.835 .

2) Hedonic/Utilitarian Product Perceptions: Hedonic value refers to product experience in the form of pleasure and fun, whereas utilitarian value refers to product experience related to functional outcomes [18]. We adapted the scales from Voss et al. [20] to evaluate the hedonic and utilitarian perceptions of subjects toward the presented products. The Cronbach's alphas for the hedonic and utilitarian dimensions were 0.872 and 0.896 , respectively.

3) Attitude: Attitude is defined as the predisposition to respond in a particular way toward the product [49]. We adapted the scale from [57] to measure the overall attitude of subjects toward a product. The Cronbach's alpha was 0.903 .

The actual measurement items for hedonic/utilitarian product perceptions and attitude are reported in the Appendix.

\section{DATA ANALYSIS}

Before we tested the hypotheses, we first conducted a series of independent sample $t$-tests for the dependent measures across the two color schemes (blue scheme vis-à-vis gray scheme). We found no significant differences in the subjects' responses. Hence, we pooled their responses across the two color schemes in the analysis. Similarly, we compared the subjects' responses across different orders of presentation and found no significant disparities.

Table II presents the descriptive statistics of the dependent measures. We used a 7-point scale for hedonic/utilitarian perceptions and overall attitude. The range of the score for recall-A was $0-4$, whereas the range of the score for recall-S was $0-5$.
TABLE II

DESCRIPTIVE STATISTICS

\begin{tabular}{|l|r|r|r|r|}
\hline & Mean & S.D. & Max & Min \\
\hline Recall-A & 3.06 & 0.786 & 4.00 & 1.00 \\
\hline Recall-S & 2.44 & 1.160 & 5.00 & 0.00 \\
\hline Hedonic Score & 4.64 & 1.098 & 6.86 & 1.71 \\
\hline Utilitarian Score & 4.75 & 1.165 & 7.00 & 1.50 \\
\hline Overall Attitude & 5.23 & 0.903 & 7.00 & 2.17 \\
\hline
\end{tabular}

TABLE III

RECALL

\begin{tabular}{|l|r|r|r|r|c|}
\hline & \multicolumn{2}{|c|}{ Animated Webpage } & \multicolumn{2}{|c|}{ Static Webpage } & \multirow{2}{*}{ t } \\
\cline { 2 - 5 } & Mean & S.D. & Mean & S.D. & \multicolumn{1}{c}{ t.7. } \\
\hline Recall-A & 3.29 & 0.762 & 2.84 & 0.750 & 3.71 \\
\hline Recall-S & 2.00 & 1.139 & 2.88 & 1.006 & -5.22 \\
\hline
\end{tabular}

TABLE IV

HEDONIC AND UTILITARIAN PERCEPTIONS

\begin{tabular}{|c|c|c|c|c|c|}
\hline & \multicolumn{2}{|c|}{ Animated Webpage } & \multicolumn{2}{|c|}{ Static Webpage } & \multirow[b]{2}{*}{$\mathbf{t}$} \\
\hline & Mean & S.D. & Mean & S.D. & \\
\hline Hedonic Score & 4.88 & 0.997 & 4.41 & 1.148 & 2.78 \\
\hline Utilitarian Score & 4.94 & 1.120 & 4.55 & 1.184 & 2.13 \\
\hline
\end{tabular}

TABLE V

Hedonic ANd Utilitarian PERCEPTIONS By PRODUCTS

\begin{tabular}{|c|c|c|c|c|c|c|}
\hline & \multicolumn{2}{|c|}{ Animated Web page } & \multicolumn{2}{|c|}{ Static Web page } & \multirow[b]{2}{*}{ Mean diff } & \multirow[b]{2}{*}{$\mathbf{t}$} \\
\hline Hedonic Value & Mean & S.D. & Mean & S.D. & & \\
\hline "Hedonic" Product & 5.41 & 0.735 & 4.88 & 1.125 & 0.53 & \multirow{2}{*}{0.38} \\
\hline "Utilitarian" Product & 4.35 & 0.950 & 3.94 & 0.975 & 0.41 & \\
\hline Utilitarian Value & Mean & S.D. & Mean & S.D. & Mean diff & $\mathbf{t}$ \\
\hline "Hedonic" Product & 4.36 & 1.049 & 3.80 & 1.055 & 0.56 & \multirow[b]{2}{*}{1.15} \\
\hline "Utilitarian" Product & 5.52 & 0.865 & 5.30 & 0.753 & 0.22 & \\
\hline
\end{tabular}

high on utilitarian value as "utilitarian" products.

To test $\mathrm{H} 1 \mathrm{a}$ and $\mathrm{H} 1 \mathrm{~b}$, we performed a series of independent sample $t$-tests on the experimental responses of recall- $A$ and recall- $S$. The results are reported in Table III. As predicted, the average score for recall- $A$ was higher for the animated Web pages than the pages with only static contents $(t=3.71, p<$ $0.05)$. By contrast, the average score for recall- $S$ was higher for static Web pages than the pages with animation $(t=-5.22, p<$ $0.05)$. Hence, both H1a and H1b were supported.

Similarly, we conducted independent sample $t$-tests to compare the utilitarian and hedonic values of the products under different presentations. The results are shown in Table IV. Animated Web pages raised the subjects' hedonic perceptions of the products relative to static Web pages $(t=2.78, p<0.05)$. Hence, H2a was supported. Contrary to H2b, however, animated Web pages also raised the subjects' utilitarian perceptions of the products $(t=2.13, p<0.05)$. Hence, $\mathrm{H} 2 \mathrm{~b}$ was rejected (in fact, the result was opposite to what we hypothesized).

We conducted two-way analysis of variance (ANOVA) to test $\mathrm{H} 3 \mathrm{a}$ and $\mathrm{H} 3 \mathrm{~b}$, which concerned about how the interaction between product nature (hedonic vis-à-vis utilitarian) and presentation type (animated vis-à-vis static) affected changes in product perceptions. The results are presented in Table V. There were no significant differences in either hedonic $(F=0.152$, $p>0.10)$ or utilitarian $(F=1.32, p>0.10)$ perceptions across the product nature $\times$ presentation type interaction. Hence, both $\mathrm{H} 3 \mathrm{a}$ and $\mathrm{H} 3 \mathrm{~b}$ were not supported. The effect of moving animation on hedonic perception was not weaker for products that 
TABLE VI

ATTITUDE TOWARD PRODUCTS

\begin{tabular}{|c|r|r|r|r|r|r|}
\hline & \multicolumn{2}{|c|}{ Animated Webpage } & \multicolumn{3}{|l|}{ Static Webpage } & \\
\hline Attitude & Mean & S.D. & Mean & S.D. & Mean Diff & t \\
\hline Hedonic Product & 5.44 & 0.800 & 4.87 & 1.002 & 0.57 & 2.80 \\
\hline Utilitarian Product & 5.18 & 1.015 & 5.45 & 0.649 & -0.27 & -1.42 \\
\hline
\end{tabular}

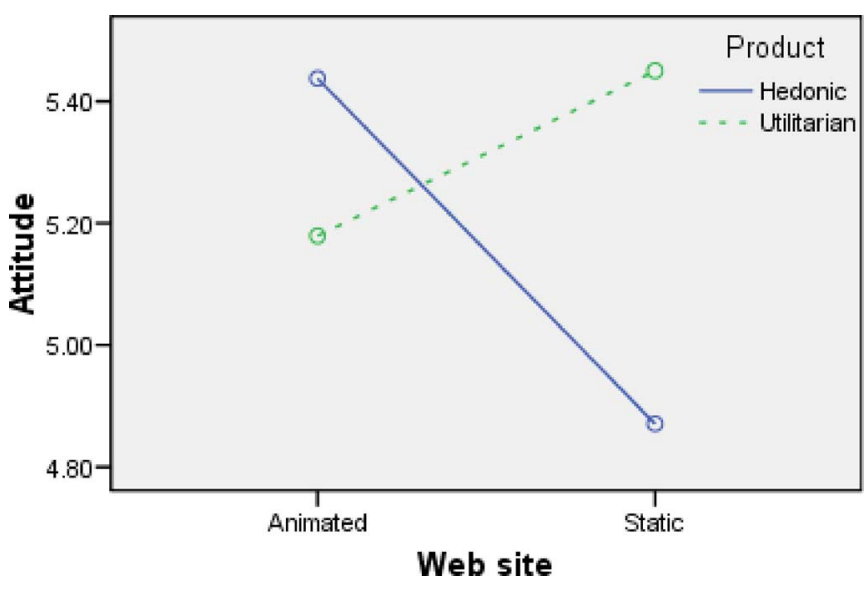

Fig. 3. Attitude toward products.

TABLE VII

SUMMARY OF RESULTS

\begin{tabular}{|l|l|l|}
\hline H1a & $\begin{array}{l}\text { The recall of animated contents is higher in a Web site exhibiting both } \\
\text { animated and static (non-animated) contents than a Web site with only } \\
\text { static contents. }\end{array}$ & Supported \\
\hline H1b & $\begin{array}{l}\text { The recall of static contents is higher in a Web site exhibiting only static } \\
\text { contents than a Web site with both animated and static contents. }\end{array}$ & Supported \\
\hline H2a & $\begin{array}{l}\text { The hedonic perception of a product is higher in a Web site exhibiting } \\
\text { both animated and static contents than a Web site with only static } \\
\text { contents. }\end{array}$ & Supported \\
\hline H2b & $\begin{array}{l}\text { The utilitarian perception of a product is higher in a Web site exhibiting } \\
\text { only static contents than a Web site with both animated and static } \\
\text { contents. }\end{array}$ & Not supported \\
\hline H3a & $\begin{array}{l}\text { The effect of moving animation on a product's hedonic value is weaker } \\
\text { for a product that is high on the hedonic dimension than a product that is } \\
\text { high on the utilitarian dimension. }\end{array}$ & Not Supported \\
\hline H3b & $\begin{array}{l}\text { The effect of static contents on a product's utilitarian value is weaker for } \\
\text { a product that is high on the utilitarian dimension than a product that is } \\
\text { high on the hedonic dimension. }\end{array}$ & Not Supported \\
\hline H4 & $\begin{array}{l}\text { The effect of moving animation on consumer attitude toward a product } \\
\text { depends on the nature of the product. Moving animation leads to higher } \\
\text { consumer attitude for products that are high on hedonic value. By } \\
\text { contrast, static contents (without animation) lead to higher attitude for } \\
\text { products that are high on utilitarian value. }\end{array}$ & $\begin{array}{l}\text { Partially } \\
\text { Supported }\end{array}$ \\
\hline
\end{tabular}

provide higher hedonic values. Similarly, the effect of static Web contents on utilitarian perception was not weaker for products that provide higher utilitarian values.

Finally, we performed another two-way ANOVA to test H4, which concerned about whether fitting product nature to Web page presentation affects consumer attitude. The results are reported in Table VI and Fig. 3. There was a significant product nature $\times$ presentation type interaction effect on overall attitude $(F=9.07, p<0.05)$. The moving animation generated more favorable attitudes toward products that were high on the hedonic dimension $(t=2.80, p<0.05)$. On the other hand, the Web pages with only static contents generated more favorable attitudes toward products that were high on the utilitarian dimension, but the difference was not statistically significant $(t=-1.42, p>0.05)$. Hence, $\mathrm{H} 4$ was partially supported.

Table VII summarizes the hypothesis testing results.

\section{DISCUSSION AND IMPLICATIONS}

This study theoretically developed and empirically validated some potential impacts of moving animation in the Web environment. The support of H1a and H1b suggests that recall was enhanced for the animated contents relative to the static ones. This is consistent with previous findings that animation, when not carrying task-related information, may deteriorate the performance on information seeking tasks [4]. These results suggest that firms and Web designers should exercise caution and business acumen when implementing animation within their Web sites. They need to determine the marketable features and important information of the product in order to animate properly, such that these features and information can be easily recollected by consumers. Conversely, they could distinguish inconsequential attributes by leaving them as static components within a Web page, as it is not essential for consumers to process or remember them.

The support of H2a suggests that moving animation could induce consumers to perceive a product as being more "hedonic." Interestingly, we found opposite results to what we hypothesized in $\mathrm{H} 2 \mathrm{~b}$ - we expected static contents on a Web page to enhance utilitarian perceptions, but, to our surprise, moving animation actually led to higher utilitarian perceptions of products than completely static contents.

One possible explanation for this intriguing finding could stem from the mediating role of consumer involvement. Previous research has suggested that pleasure could lead to involvement [58]. Since moving animation arouses consumers and leads to a fun and vivid environment [3], [4], it may facilitate higher involvement in the Web page too. Such involvement may lead to more time and effort expended by subjects to pursue the items on the Web page [59].

In our experiment, the Web pages consisted of descriptions on the functionality and features of the products. If highly involved people attended to more information, they may be able to process more functionality and features of the displayed products. This might subsequently lead to higher perceived utilitarian values of the products. To validate this explanation, however, it is useful for future research on moving animation to account for the extent of consumer involvement in the experimental design.

The results on $\mathrm{H} 3 \mathrm{a}$ and $\mathrm{H} 3 \mathrm{~b}$ suggest that, while moving animation enhances both the hedonic and utilitarian values of a product, the incremental contribution due to moving animation is similar for both the hedonic and utilitarian dimensions. One cautionary note, however, is that we used simple manipulations of moving animation in our experiment, and we did not vary the level of animation (in the form of different speed, intensity, etc. multiple levels of stimuli were often used in psychometric scaling of consumer responses, and it was the basis for establishing Weber's law; see, e.g., [43], [46]). It is possible that more salient and advanced animations could arouse different extents of changes in product perceptions. Future research should reexamine these two hypotheses in a more general setting, perhaps by using different types or levels of animation stimuli.

The outcome of $\mathrm{H} 4$ demonstrates the importance of fitting moving animation to product nature. Moving animation may help elevate consumer attitude for products that are high on the 
hedonic dimension, but it may not work for products that are "utilitarian" in nature. Practically, this implies that online firms need to be cautious when exhibiting products on a Web site. They should understand their products and the premeditated positions of the products well when contemplating to use moving animation or when deciding to exhibit purely static contents. Products that deliver hedonic values may deserve the extended implementation efforts and costs of moving animation; however, for products that are "utilitarian," such efforts and costs may not be justifiable. Indeed, moving animation could even lower consumer attitude for such products since it may unnecessarily arouse and distract consumers.

One good area for future research is to study how animation affects consumer responses on mobile phones or other personal handheld devices, which typically have smaller screen sizes and slower data transmission speed [60], [61]. Owing to limited device capability, animation has not been commonly deployed in mobile commerce, which (ironically) often involves "hedonic" products such as music, ringtone and movie downloads, and online multiplayer games. It would be helpful to explore if animation could facilitate the success of mobile commerce by encouraging the consumption of products that are high on the hedonic dimension. Such products could well be the "killer apps" for mobile commerce, which to date seems to have been slow in taking off [62].

On the other hand, for "utilitarian" products on mobile platforms such as real-time news, or email and general messaging services, our research implies that the mobile industry could do better by emphasizing the functional aspects of the products. This could possibly explain why Blackberry ${ }^{\circledR}$, which allowed users to send and receive electronic messages in a straightforward manner without overly sophisticated and complicated user interface and animation, has enjoyed tremendous popularity and success among business users.

Our research also sheds some lights on digital divide [63]. Past studies and implementation of digital divide have mostly advocated the importance of education and availability of resources to the elders [64]-[66]. However, research has found that the elders may not be able to process and handle animated stimuli well because of weaker visual and cognitive processing abilities [67], [68]. Hence, to close the divide, instead of emphasizing education or resources, one might need to be more discretionary in promoting the benefits of the Internet. In particular, elderly people may more likely use the Internet if "utilitarian" products and static Web pages are offered in combination. By contrast, it might be difficult for hedonic products to appeal to such users, since at the outset they may not be able to process animated stimuli well.

From a theoretical perspective, this study looks beyond the traditional animation research on banner advertisements (which typically occupies a small section of a Web page) and focuses on how animation of an entire Web page would affect the presentation of a product. Further, it is also a pioneer attempt to fill the disparity between moving animation and hedonism/utilitarianism research — an amalgamation which may have significant influence on dictating the future adoption of moving or other types of animation.
For engineers or technology managers, this study echoes the importance of appreciating the marketing aspects when developing Web stimuli [69], and it stresses the importance of understanding the consumers when designing an online storefront [70]. The timing of Web stimuli such as animation speed [3], pop-up promotions [71], or download time [72], and, as we found in this study, the use of moving animations, could inadvertently shape consumer attitude and responses. It is important for technology managers to recognize that elegant and sophisticated technologies may not always "do the trick" in attracting consumers. If not properly designed, managed, and targeted at the right audience, such technologies could even lead to poor perceptions and turn away consumers [4], [72].

\section{CONCLUDING REMARKS}

There are some limitations in this study. First, our stimuli consisted of only one Web page, which might be insufficient in replicating the effects of a real Web site on consumers. Second, since we conducted a laboratory experiment, the subjects were instructed to browse the Web pages in a somewhat "forced" exposure situation. It would be more insightful if the study can be replicated in a real field setting. Third, it may be helpful if additional measures were used to specifically evaluate subjects' perceived fit between product nature and the use of moving animation within a Web site. Familiarity with a product could also pose as a factor that affects the dependent measures, particularly recall.

As we mentioned earlier, future research should explore the potential mediating role of involvement in the Web site-attitude relationship. One can possibly draw practical insights by delving into the subsequent effects of animation too, such as consumers' purchase intention. Finally, it may be interesting and useful to understand how animation can create differing degrees of compelling online experiences across different product categories by applying or scrutinizing the concept of flow [73].

Overall, engineers, technology managers, and general Web developers should habitually rationalize the use of moving animation against its weaknesses. If a firm institutes animation in a Web site fortuitously, then the relative simplicity, accessibility, and ease of apprehension of a static HTML Web site might be a wiser choice. Our results offer a thoughtful consideration that may lead to a worthier marketing investment. The finding - that moving animation enhances consumer attitude only if it fits the product nature (H4) - is particularly noteworthy, as it implies that nondiscriminatory use of moving animations could lead to lower consumer attitude and worse firm performance. It certainly does not pay to add costly and fanciful animations only to make people feel bad about your product.

\section{APPENDIX}

Measurement items used in this study (all items were measured by 7-point scales).

Utilitarian Value

1) I rely on this produce to fulfill my basic needs

2) This product is functional.

3) This product is helpful. 
4) This product is necessity for me.

5) This product is practical.

6) This product is effective.

\section{Hedonic Value}

1) This product is fun.

2) This product is thrilling.

3) This product is enjoyable.

4) Using this product makes me look good.

5) This product is exciting.

6) Using this product makes me feel good.

7) This product is delightful.

Attitude toward a product

1) Bad/Good

2) Unfavorable/Favorable

3) Unpleasant/Pleasant

4) Disagreeable/Agreeable

5) Worthless/Valuable

6) Negative/Positive

\section{REFERENCES}

[1] S. S. Sundar, G. Otto, L. Pisciotta, and K. Schlag, "Animation and priming effects in online advertising," presented at the Annu. Conv. Assoc. Educ. Journalism Mass Commun., Chicago, IL, 1997.

[2] W. Hong, J. Y. L. Thong, and K. Y. Tam, "Does animation attract online users' attention? The effects of flash on information search performance and perceptions," Inform. Syst. Res., vol. 15, no. 1, pp. 60-86, 2004.

[3] S. S. Sundar and S. Kalyanaraman, "Arousal, memory, and impressionformation effects of animation speed in web advertising," J. Advertising, vol. 33, no. 1, pp. 7-17, 2004.

[4] P. Zhang, "The effects of animation on information seeking performance on the World Wide Web: Securing attention or interfering with primary tasks?" J. Assoc. Inform. Syst., vol. 1, no. 1, pp. 1-28, 2000.

[5] D. T. Schaller, S. Allison-Bunnell, E. Web, A. C. Adventures, P. Marty, and M. Heo, "To flash or not to flash? Usability and user engagement of HTML vs. Flash," presented at the Museums Web 2004 Int. Conf., Vancouver, BC, Canada.

[6] Z. Jiang and I. Benbasat, "Investigating the influence of the functional mechanisms of online product presentations," Inform. Syst. Res., vol. 18, no. 4, pp. 454-470, 2007.

[7] B. Fasolo, R. Misuraca, G. H. McClelland, and M. Cardaci, "Animation attracts: The attraction effect in an on-line shopping environment," Psychol. Marketing, vol. 23, no. 10, pp. 799-811, 2006.

[8] R. Dhar and K. Wertenbroch, "Consumer choice between hedonic and utilitarian goods," J. Marketing Res., vol. 37, no. 1, pp. 60-71, 2000

[9] R. Vaughn, "How advertising works: A planning model revisited," $J$. Advertising Res., vol. 26, no. 1, pp. 57-66, 1986.

[10] R. Baecker and I. Small, "Animation at the interface," in The Art of Human-Computer Interface Design, B. Laurel and S. J. Mountford, Eds. Reading, MA: Addison-Wesley, 1990, pp. 251-267.

[11] B. Reeves and C. Nass, The Media Equation: How People Treat Computers, Television, and New Media Like Real People and Places. New York: Cambridge Univ. Press, 1996.

[12] A. G. Cropper and S. J. W. Evans, "Ergonomics and computer display design," Comput. Bull., vol. 12, no. 3, pp. 94-98, 1968.

[13] H. Li and J. L. Bukovac, "Cognitive impact of banner Ad characteristics: An experimental study," Journalism Mass Commun. Quart., vol. 76, no. 2, pp. 341-353, 1999.

[14] B. H. Detenber and B. Reeves, "A bio-informational theory of emotion: Motion and image size effects on viewers," J. Commun., vol. 46, no. 3, pp. 66-84, 1996.

[15] A. Hamilton (1998, Aug. 19). Secrets of super-high web Ad clickthrough. ZDNet. [Online]. Available: http://www.zdnet.com/anchordesk/ story/story_2439.html

[16] R. Briggs and N. Hollis, "Advertising on the web: Is there response before click-through," J. Advertising Res., vol. 37, no. 2, pp. 33-45, 1997.
[17] E. C. Hirschman and M. B. Holbrook, "Hedonic consumption: Emerging concepts, methods and propositions," J. Marketing, vol. 46, no. 3, pp. $92-$ 101, 1982.

[18] B. J. Babin, W. R. Darden, and M. Griffin, "Work and/or fun: Measuring hedonic and utilitarian shopping value," J. Consum. Res., vol. 20, no. 4 , pp. 644-656, 1994.

[19] M. Strahilevitz and J. G. Myers, "Donations to charity as purchase incentives: How well they work may depend on what you are trying to sell," $J$. Consum. Res., vol. 24, no. 4, pp. 434-446, 1998.

[20] K. E. Voss, E. R. Spangenberg, and B. Grohmann, "Measuring the hedonic and utilitarian dimensions of consumer attitude," J. Marketing Res., vol. 40, no. 3, pp. 310-320, 2003.

[21] R. Batra and O. T. Ahtola, "Measuring the hedonic and utilitarian sources of consumer attitudes," Marketing Lett., vol. 2, no. 2, pp. 159-170, 1991.

[22] W. W. Moe and P. S. Fader, "Uncovering patterns in cybershopping," California Manage. Rev., vol. 43, no. 4, pp. 106-117, 2001.

[23] J. W. Overby and E. J. Lee, "The effects of utilitarian and hedonic online shopping value on consumer preference and intentions," J. Bus. Res., vol. 59, no. 10-11, pp. 1160-1166, 2006.

[24] M. B. Holbrook and E. C. Hirschman, "The experiential aspects of consumption: Consumer fantasies, feelings, and fun," J. Consum. Res., vol. 9, no. 2, pp. 132-140, 1982.

[25] W. W. Moe and P. S. Fader, "Dynamic conversion behavior at e-commerce sites," Manage. Sci., vol. 50, no. 3, pp. 326-335, 2004.

[26] T. H. Davenport and J. C. Beck, "The attention economy," Ubiquity, vol. 2 , no. 14 , p. $1,2001$.

[27] G. DeSanctis, "Computer graphics as decision aids: Directions for research," Decision Sci., vol. 15, no. 4, pp. 463-487, 1984.

[28] A. Large, "Multimedia and comprehension: A cognitive study," J. Amer. Soc. Inform. Sci., vol. 45, no. 7, pp. 515-528, 1994.

[29] N. S. Umanath, R. W. Scamell, and S. R. Das, "An examination of two screen/report design variables in an information recall context," Decision Sci., vol. 21, no. 1, pp. 216-240, 1990

[30] A. Lang, "The limited capacity model of mediated message processing," J. Commun., vol. 50, no. 1, pp. 46-70, 2000.

[31] B. J. Babin and J. S. Attaway, "Atmospheric affect as a tool for creating value and gaining share of customer," J. Bus. Res., vol. 49, no. 2, pp. $91-$ 99, 2000

[32] R. E. Milliman, "The influence of background music on the behavior of restaurant patrons," J. Consum. Res., vol. 13, no. 2, pp. 286-289, 1986.

[33] J. Kim, J. Lee, K. Han, and M. Lee, "Businesses as buildings: Metrics for the architectural quality of internet businesses," Inform. Syst. Res., vol. 13, no. 3, pp. 239-254, 2002.

[34] M. Koufaris, "Applying the technology acceptance model and flow theory to online consumer behavior," Inform. Syst. Res., vol. 13, no. 2, pp. 205223, 2002.

[35] A. L. Montgomery, S. Li, K. Srinivasan, and J. C. Liechty, "Modeling online browsing and path analysis using clickstream data," Marketing Sci., vol. 23, no. 4, pp. 579-595, 2004.

[36] X. Zhang and V. R. Prybutok, "A consumer perspective of e-service quality," IEEE Trans. Eng. Manage., vol. 52, no. 4, pp. 461-477, Nov. 2005.

[37] U. M. Dholakia and L. L. Rego, "What makes commercial web pages popular?" Eur. J. Marketing, vol. 32, no. 7/8, pp. 724-736, 1998.

[38] B. H. Thomas and P. Calder, "Applying cartoon animation techniques to graphical user interfaces," ACM Trans. Comput.-Human Interaction, vol. 8, no. 3, pp. 198-222, 2001.

[39] V. D. Kaltcheva and B. A. Weitz, "When should a retailer create an exciting store environment?" J. Marketing, vol. 70, no. 1, pp. 107-118, 2006.

[40] T. J. Olney, M. B. Holbrook, and R. Batra, "Consumer responses to advertising: The effects of Ad content, emotions, and attitude toward the Ad on viewing time," J. Consum. Res., vol. 17, no. 4, pp. 440-453, 1991.

[41] J. M. Kamen and R. J. Toman, "Psychophysics of prices," J. Marketing Res., vol. 7, no. 1, pp. 27-35, 1970.

[42] K. B. Monroe, "Psychophysics of prices-Reappraisal," J. Marketing Res., vol. 8, no. 2, pp. 248-250, 1971.

[43] V. R. Rao and G. W. Wilcox, "Multidimensional psychophysics: An overview," Adv. Consum. Res., vol. 1, pp. 154-165, 1974.

[44] A. W. Freeman and D. R. Badcock, "Visual sensitivity in the presence of a patterned background," J. Opt. Soc. Amer. A, Opt. Image Sci. Vis., vol. 16, no. 5, pp. 979-986, 1999.

[45] J. H. Shen and Y. M. Jung, "Weberized Mumford-Shah model with BoseEinstein photon noise," Appl. Math. Opt., vol. 53, no. 3, pp. 331-358, 2006. 
[46] S. S. Stevens, "On the psychophysical law," Psychol. Rev., vol. 64, no. 3, pp. $153-181,1957$.

[47] R. L. Miller, "Dr. Weber and the consumer," J. Marketing, vol. 26, no. 1, pp. 57-61, 1962.

[48] J. M. Kamen and R. J. Toman, "Psychophysics of prices—Reaffirmation," J. Marketing Res., vol. 8, no. 2, pp. 252-257, 1971.

[49] M. J. Rosenberg, "An analysis of affective-cognitive consistency," in Attitude Organization and Change, M. J. Rosenberg and C. I. Hovland, Eds. New Haven, CT: Yale Univ. Press, 1960, pp. 15-64.

[50] R. M. Perloff, The Dynamics of Persuasion. Hillsdale, NJ: Lawrence Erlbaum Associates, 1993.

[51] S. Oskamp and P. W. Schultz, Attitudes and Opinions. Mahwah, NJ: Lawrence Erlbaum Associates Inc., 2005.

[52] J. Huber, J. W. Payne, and C. Puto, "Adding asymmetrically dominated alternatives: Violations of regularity and the similarity hypothesis," $J$. Consum. Res., vol. 9, no. 1, pp. 90-98, 1982.

[53] S. S. Sundar and J. Kim, "Interactivity and persuasion: Influencing attitudes with information and involvement," J. Interactive Advertising, vol. 5, no. 2, pp. 6-29, 2005.

[54] B. Müller and J. L. Chandon, "The impact of a world wide web site visit on brand image in the motor vehicle and mobile telephone industries," $J$. Marketing Commun., vol. 10, no. 2, pp. 153-165, 2004.

[55] C. W. Park, S. Milberg, and R. Lawson, "Evaluation of brand extensions: The role of product feature similarity and brand concept consistency," $J$. Consum. Res., vol. 18, no. 2, pp. 185-193, 1991.

[56] S. T. Hong and R. S. Wyer, "Determinants of product evaluation: Effects of the time interval between knowledge of a product's country of origin and information about its specific attributes," J. Consum. Res., vol. 17, no. 3, pp. 277-288, 1990.

[57] L. A. Crosby and S. L. Grossbart, "A blueprint for consumer behavior research on personality," in Advances in Consumer Research, T. C. Kinnear, Ed. Provo, UT: Association for Consumer Research, 1984, pp. 447-452.

[58] G. Laurent and J. N. Kapferer, "Measuring consumer involvement profiles," J. Marketing Res., vol. 22, no. 1, pp. 41-53, 1985.

[59] R. N. Stone, "The marketing characteristics of involvement," Adv. Consum. Res., vol. 11, no. 1, pp. 210-215, 1984.

[60] M. Chae and J. Kim, "Do size and structure matter to mobile users? An empirical study of the effects of screen size, information structure, and task complexity on user activities with standard web phones," Behav. Inform. Technol., vol. 23, no. 3, pp. 165-181, 2004.

[61] N. Maniar, E. Bennett, S. Hand, and G. Allan, "The effect of mobile phone screen size on video based learning," J. Softw., vol. 3, no. 4, pp. 51-61, 2008

[62] J. J. Zhang, Y. Yuan, and N. Archer, "Driving forces for m-commerce success," J. Internet Commerce, vol. 1, no. 3, pp. 81-106, 2002.

[63] S. Dewan and F. J. Riggins, "The digital divide: Current and future research directions," J. Assoc. Inform. Syst., vol. 6, no. 12, pp. 298-337, 2005.

[64] L. Kvasny and M. Keil, "The challenges of redressing the digital divide: A tale of two US cities," Inform. Syst. J., vol. 16, no. 1, pp. 23-53, 2006.

[65] D. Law, "Bridging the digital divide: A review of current progress," $\mathrm{Li}$ brary Manage., vol. 25, no. 1-2, pp. 17-21, 2004.

[66] G. Murdock, "Review article: Debating digital divides," Eur. J. Commun., vol. 17, no. 3, pp. 385-390, 2002.

[67] J. K. Eastman and R. Iyer, "The impact of cognitive age on internet use of the elderly: An introduction to the public policy implications," Int. J. Consum. Stud., vol. 29, no. 2, pp. 125-136, 2005.

[68] L. Wang, H. Sato, L. Jin, P. Rau, and Y. Asano, "Perception of movements and transformations in flash animations of older adults," Lecture Notes Comput. Sci., vol. 4550, pp. 966, 2007.

[69] D. L. Johnstone, "Engineering contributions to the evolution of management practice," IEEE Trans. Eng. Manage., vol. 36, no. 2, pp. 105-113, May 1989.

[70] P. Tarasewich and S. K. Nair, "Designer-moderated product design," IEEE Trans. Eng. Manage., vol. 48, no. 2, pp. 175-188, May 2001.

[71] W. W. Moe, "A field experiment to assess the interruption effect of pop-up promotions," J. Interactive Marketing, vol. 20, no. 1, pp. 34-44, 2006.

[72] G. M. Rose, R. Evaristo, and D. Straub, "Culture and consumer responses to web download time: A four-continent study of mono and polychronism," IEEE Trans. Eng. Manage., vol. 50, no. 1, pp. 31-44, Feb. 2003.

[73] T. P. Novak, D. L. Hoffman, and Y. F. Yung, "Measuring the flow construct in online environments: A structural modeling approach," Marketing Sci., vol. 19 , no. 1 , pp. $22-44,2000$.

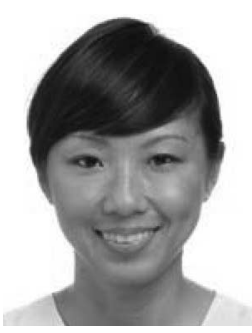

Yee-Lin Lai received the B.Sc. (with honors) and $\mathrm{Ph} . \mathrm{D}$. degrees in information systems from the $\mathrm{Na}-$ tional University of Singapore, Singapore.

Her work experiences include teaching and research assistantship in the National University of Singapore, and she was a Visiting Scholar at the University of California at Berkeley in 2005. She is currently with the Department of Technology Commercialization, Agency for Science, Technology and Research, Singapore, where she is engaged with innovation and technology transfer strategy. Her recent research interests include information privacy, online interactions, and Web consent mechanisms.

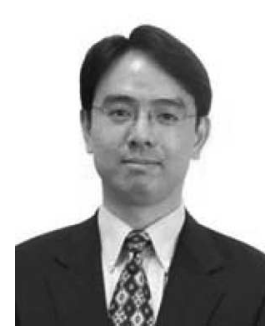

Kevin K. Y. Kuan received the Doctoral degree in computer and information systems from the University of Michigan, Ann Arbor.

$\mathrm{He}$ is an Assistant Professor at the Department of Information Systems, City University of Hong Kong, Kowloon, Hong Kong. His research interests include human-computer interaction, information presentation and decision making, reputation systems, and IS/IT adoption and implementation. His works have appeared in journals and conferences such as the Communications of the Association of Information Systems, European Journal of Information Systems, Information and Management, and the International Conference on Information Systems.

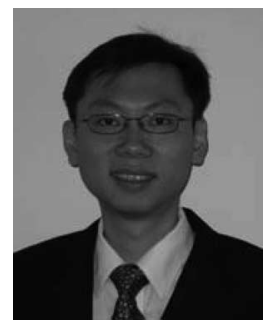

Kai-Lung Hui received the Doctoral degree in information systems from the Hong Kong University of Science and Technology, Kowloon, Hong Kong.

$\mathrm{He}$ is an Associate Professor at the Department of Information Systems, Business Statistics and Operations Management, the Hong Kong University of Science and Technology. His research interests include privacy, pricing and timing new technologies, and social interaction. His research has been published in scholarly journals including American Economic Review: Papers and Proceedings, Management Science, MIS Quarterly, and Journal of MIS, among others.

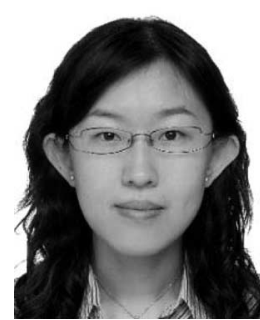

Na Liu received the B.S. degree (with honors) in computing from the Department of Information Systems, National University of Singapore, Singapore, in 2006, where she is currently working toward the Doctoral degree.

She is currently a Teaching Assistant in the Department of Information Systems, National University of Singapore. Her research interests include collaborative technologies, learning technologies, and human-computer interactions. Her works have been published in several international conferences, including Hawaii International Conference on System Sciences (HICSS), Pacific Asia Conference on Information Systems (PACIS), International Conference on Human-Computer Interaction (HCII), and the International Federation for Information Processing Working Group 8.2 Conference (IFIP WG8.2). 